\title{
A vision for space science
}

\section{Giovanni F. Bignami}

Received: 6 January 2009 / Accepted: 6 January 2009 / Published online: 16 January 2009

(C) Springer Science + Business Media B.V. 2009

The effort made in 2004/2005 by the European Space Science community to bring about the Cosmic Vision long-term programme set a standard to spacefaring Agencies for the third time in history. We think that the long-term space science programme of ESA is the only example of planned and formalized cooperation between a whole scientific community and an agency, in this case a multinational organization. It is easier said than done, but Europe did it, already three times.

It is nice to think that there is now the chance to hand over to posterity, in printed form as a complement to the original ESA report, the present collection of 41 refereed papers. They are a representative sample of the 49 proposals originally submitted by the space science community, and on which the Cosmic Vision programme is based. The selection procedure for this volume was first of all related to the willingness of authors to actually put in scientific paper form their original proposals, secondly for them to accept the idea of rendering their work public and finally to enforce a particularly scrutinous refereeing process.

However, this is only one part of the picture. Having participated (one of us as Chair of the ESA Space Science Advisory Committee) to the Cosmic Vision exercise, we would like to briefly outline here three other important elements, which were, and still are, at the heart of the programme.

First of all, there is the idea itself of a long term programme, conceived from the start to be as binding as any plan can be. One does so consciously, in spite

G. F. Bignami $(\bowtie)$

IUSS - Institute for Advanced Studies, Pavia, Italy

e-mail: giovanni.bignami@gmail.com

G. F. Bignami

Istituto di Astrofisica Spaziale - INAF, Milan, Italy 
of knowing that, of course, the future can be influenced by many factors, most of them escaping the control of the planners. Especially for the two previous programmes, Horizon 2000 (1983/1984, with Edoardo Amaldi in the SSAC Chair) and Horizon 2000 Plus (1994/1995, with Lo Woltjer) respectively, it was possible for the ESA Executive to adhere to both plans with astonishing precision. Scientists knew that what they contributed to was not a joke: if their mission had been selected, sooner or later its turn would come, without all those uncertainties, delays, cancellations and resurrections, which are so frequent in other programmes, other Agencies, other Organizations.

Secondly, there is the very machinery of our planning exercise. Here you have the scientific community, often flanked by their industry experts, on the one side, and ESA on the other, the latter represented by a relatively small executive force. The critical interface between the two parts of the machine is composed by the three working groups (Astronomy, Solar System and Fundamental Physics) and the Space Science Advisory Committee. About 50 people all together, neither too many nor too few. No European space scientist can say that he/she did not have the opportunity to make a proposal, to defend it and finally to have it judged by peers. Decisions were not taken by bureaucrats, no matter how enlightened.

In the space science community of Europe we are so accustomed to these two elements, that perhaps we fail to appreciate how innovative they have been. They were put together in the early Eighties by the founding fathers of the first Horizon 2000 Programme, among them, above all, Roger Bonnet. They were instrumental in giving Europe a special status among space-faring agencies. Still today, they represent a tradition which we cherish and which we were proud to continue at the time of the Cosmic Vision exercise. It is mainly thanks to such a tradition that the visibility and charisma of European space science far exceeds the budget of the ESA space science programme itself.

There is also a third element, i.e. how to make the plan known and acceptable to the whole scientific community. This is the last task before implementation, and in general it is carried out just before an ESA Ministerial Conference, in the hope that Ministers understand the need to grant appropriate funds to the Science Programme of ESA. One must remember that the Science Programme has been from the start, and remains today and for the foreseeable future, the only mandatory programme of ESA. We would like to explain once more a home truth which, I have noticed, in general is not fully understood. The mandatory status of the programme was decided very early in the history of ESA (when it was still called ESRO) to protect its funding to science, and everybody understands that. But it remains a programme which as fragile as science itself. In it are the basis of all future application developments, but, of course, by itself it does not yield any immediate fallback, especially in terms of economical return for the investment. In fact, its return cannot be evaluated easily, other than by saying that thanks to it we are all enriched by feeling a little bit less ignorant. To complicate matters, the crucial decision on the three-year funding (the level of resources) for the science programme must be taken unanimously. All Ministers, therefore, must unanimously share 
this need to feel less ignorant. This is not always easy to obtain. So, to the question: why is the science programme protected? Is it to protect the innocent games of European scientists? The correct answer, we have now learnt perhaps with some surprise, is that science is only one face of the value of the science programme. The other face, at least equally important, is its content in technological innovation. The space science missions (along with the Earth Observation Envelope Progamme missions) are the most challenging and innovative missions at ESA, both from the mission planning and management point of view and from the technological point of view.

Thus Cosmic Vision was made. I remember that the scientific community was extremely excited when ESA issued the call for proposals. Actually, the Executive had been hovering in doubt for a long time, because the Science Programme was under financial pressure as it had never been before. However, scientists made it known that they wanted to get to work as soon as possible, no matter how long would the plan take to materialize. Perhaps 1,000 scientists and engineers all over Europe worked at the proposals, creating truly European consortia. In the end, the 49 proposals we mentioned abovea record number-were sent to ESA. As predictable, they were ordered into four categories, i.e. solar system research, astronomy, fundamental physics and miscellaneous. Through the efforts of the present editor of "Astrophysical Instruments and Methods", no less than 41 proposals among those 49 have now been made available for publication. The sample is quite representative. There are 19 Astronomy proposals (39 were submitted), seven in Fundamental Physics (36), 14 in Solar System (56).

The present set of three volumes will serve as an invaluable reference for the current and future generations of scientists, engineers and industrialists. Selections of the missions have started, although various problems have somehow delayed the start of the programme. In any case, the few missions which eventually will fly are certainly present among the 49 proposals and, we are sure, are also in the present sample. It only adds a pinch of suspense that we don't yet know exactly which ones. It will be instructive to re-read these volumes after the final selection is made.

We can already say, however, that the Cosmic Vision exercise has, on the whole, obtained a very important result: ESA Ministers met in The Hague at the end of November 2008 and were obviously impressed by our exercise. We can't say exactly which inspiration descended upon them, but in the end ESA's Science Programme, that old battle-scarred workhorse, carried the day and came home from The Hague with a very solid financial result and one that gives everyone confidence, at least, for the next 3 years. And now, dear Europe space science community, it's up to you. 